\title{
O DIREITO FUNDAMENTAL À INTIMIDADE E A PERSECUÇÃO CRIMINAL NO TJ-RS: ANÁLISE DE CASO
}

THE FUNDAMENTAL RIGHT TO INTIMACY AND CRIMINAL PERSECUTION IN THE RIO GRANDE DO SUL COURT OF APPEALS: A CASE ANALYSIS

Rogério Gesta Leal ${ }^{1}$ Yuri Schneider ${ }^{2}$

Resumo: No presente leading case propõe-se um estudo acerca da verificação da amplitude da medida do Direito Fundamental Individual à Intimidade e Privacidade de pessoa física, ou seja, até que ponto pode se impor em face de interesse público indisponível, em especial diante das obrigações do Estado Democrático de Direito em apurar responsabilidade penal de natureza pública incondicionada, avaliando, para tanto, um caso judicial decidido pelo Segundo Grupo Criminal do Tribunal de Justiça do Estado do Rio Grande do Sul.

Palavras-chave: Direitos fundamentais individuais. Intimidade. Obrigação estatal.

\begin{abstract}
The present leading case proposes a study on the verification of the extent of the measure of Individual Fundamental Right to Personal Intimacy and Privacy, that is to say to what extent it can be imposed in the face of an unavailable public interest, especially in the face of the obligations of the Democratic State of Right to establish criminal liability of an unconditional public nature, evaluating, for this purpose, a judicial case decided by the Second Criminal Group of the Court of Justice of the State of Rio Grande do Sul.
\end{abstract}

Keywords: Individual fundamental rights. Intimacy. State obligation.

1 Doutor em Direito pela Universidade Federal de Santa Catarina; Professor no PPGD - Mestrado e Doutorado em Direito da Universidade de Santa Cruz do Sul e da Faculdade Municipal de Palhoça; Desembargador do Tribunal de Justiça do Estado do Rio Grande do Sul; gestaleal@gmail.com

2 Mestre e Doutor em Direito Público pela Universidade do Vale dos Sinos; Professor no PPGD - Mestrado em Direito da Universidade do Oeste de Santa Catarina; Professor de Direito Administrativo e Econômico da Graduação e Pós-Graduação da Fundação Escola Superior do Ministério Público do Estado do Rio Grande do Sul; Avenida Nereu Ramos, 3777D, Seminário, 89813-000, Chapecó, Santa Catarina, Brasil; yurisdr@hotmail.com 


\section{Notas Introdutórias}

O tema do Direito à Intimidade tem sido recorrente em vários debates e reflexões no âmbito de diversos campos da Teoria do Direito e da Pragmática Jurídica, tanto na esfera pública (investigações criminais e de responsabilidade civil ou administrativa) quanto na privada (sigilo de banco de dados, acesso a informações pessoais), notadamente em sociedades com os níveis de exposição física e virtual como a que vivemos.

A proteção da privacidade de pessoas físicas e jurídicas é exposta cotidianamente por relações comerciais, financeiras, tributárias e cadastrais, nacional e internacionalmente, desafiando sistemas jurídicos tradicionais em face do tratamento que até há pouco vinha sendo dado a ela.

A personalidade jurídica reconhece que ao cidadão importa o direito de segurança à sua vida e propriedade de um modo geral. Dentre esses direitos inclui-se o direito de intimidade, expresso como um direito fundamental, como, por exemplo, à proteção de sua intimidade física e intelectual, a intimidade da aparência, imagem e reputação, a proteção de seu íntimo, sua vida privada contra um escrutínio público indevido, etc.

Todavia, a ideia de que esse direito à intimidade seria intocável por ser fundamental foi perdendo sustentação aos poucos na história recente da doutrina e da jurisprudência internacional, fruto principalmente de algumas revisões sobre a sua natureza jusfundamental absoluta, e mesmo diante de situações de ordem pública que reclamam a flexibilização desse entendimento, sem jamais deixar de reconhecer que se trata de uma garantia constitucional que deve ser preservada.

O objeto de estudo neste artigo é verificar em que medida o Direito Fundamental Individual à Intimidade e Privacidade de pessoa física pode se impor em face de interesse público indisponível, em especial diante das obrigações do Estado Democrático de Direito em apurar responsabilidade penal de natureza pública incondicionada, avaliando, para tanto, um caso judicial decidido pelo Segundo Grupo Criminal, do Tribunal de Justiça do Estado do Rio Grande do Sul, a partir de voto divergente prolatado por um dos autores deste estudo de caso.

\section{1 É o Direito Fundamental Individual à Intimidade e Privacidade absoluto?}

Sobre o direito à intimidade deve-se lembrar da lição de Robert Alexy ao mencionar, em sua obra Teoria dos Direitos Fundamentais, a Teoria das Esferas, pela qual é possível separar três esferas com decrescente intensidade de proteção, quais sejam: a esfera mais interna (âmbito último intangível da liberdade humana), caracterizando-se por ser o núcleo mais íntimo e, conforme interpretação do Tribunal Constitucional alemão, o núcleo absolutamente protegido da organização da vida privada, compreendendo os assuntos mais secretos que não devem chegar ao conhecimento dos outros em razão de sua natureza extremamente reservada; a esfera privada ampla, que abarca o âmbito privado à medida que não pertença à esfera mais interna, incluindo assuntos que o indivíduo 
leva ao conhecimento de outra pessoa de sua confiança, ficando excluído o resto da comunidade; e a esfera social, que engloba tudo o que não for incluído na esfera privada ampla (ALEXY, 2010, p. 119).

Com o objetivo de se encontrar esse âmbito mais íntimo e interno do indivíduo, bastaria indagar se existe um comportamento de uma pessoa que, em nenhum aspecto, refira-se ou afete a esfera de outras ou os interesses da vida em comunidade. Assim, determinadas situações e formas de comportamento do indivíduo conduziriam a uma prioridade absoluta do princípio da liberdade negativa, conjuntamente com o princípio da dignidade da pessoa, frente a quaisquer princípios opostos concebíveis. Entretanto, vale lembrar que não há direito absoluto, mas ainda que assim se considere, não resta afastado o nível mais interno da personalidade do indivíduo a ser assegurado por regras ou princípios.

Relevante também ressaltar a lição de Edilsom Pereira de Farias (2000, p. 140), no sentido de que a intimidade, como exigência moral da personalidade para que em determinadas situações seja o indivíduo deixado em paz, constituindo um direito de controlar a indiscrição alheia nos assuntos privados que somente a ele interessam, tem como um de seus fundamentos o princípio da exclusividade. Esse princípio, visando a amparar a pessoa dos riscos oriundos da pressão social niveladora e da força do poder político, comporta essencialmente três exigências: a solidão (donde o desejo de estar só), o segredo (donde a exigência de sigilo), e a autonomia (donde a liberdade de decidir sobre si mesmo como centro emanador de informações). ${ }^{3}$

No espaço público, a mesma situação que ocorre com o direito à honra vem sendo aceito pela doutrina como relevante para a operacionalização ou não do direito à intimidade. Quando o agente público (servidor público ou aquele que, de alguma forma, interage som o serviço público) pratica atos inerentes a seu cargo ou função, ele se rende à exposição de sua privacidade e intimidade, considerando a relevância de seus atos perante a sociedade. Dessa forma, é de se constatar que o direito à privacidade oferece maior proteção aos cidadãos comuns do que aos homens públicos ou pessoas célebres. No entanto, verifica-se com bastante propriedade que as pessoas públicas supramencionadas não sofrem supressão de sua intimidade, mas mera limitação.

É o que expõe Nogueira Alcalá (2013), no sentido de que o alcance do direito à liberdade de informação implica que as pessoas de relevância pública, especialmente as autoridades públicas (governo, administração, legisladores, juízes), que detêm a faculdade de decidir os destinos da sociedade, têm dimensões da vida privada mais reduzidas que as pessoas que não são figuras públicas, podendo informar-se dos atos da vida pessoal que dizem respeito ou que têm implicâncias diretas com o cumprimento das obrigações públicas, mas não a respeito dos aspectos da intimidade que não são necessários nem estão vinculados com as exigências de informação de caráter relevante ou de interesse público. ${ }^{4}$

3 Ver Silva (1998, p. 2) e também o texto de Gentot (2012).

EJJL 
Assim, nos casos que a informação não seja de relevância pública prevalece o direito à privacidade da pessoa, já que a liberdade de informação se impõe somente quando seu conteúdo é de relevância pública.

Portanto, a relevância pública da informação, da livre expressão, será o único argumento legítimo para a publicação de fatos e atos que afetem a privacidade de determinado indivíduo. Ou seja, os meios de comunicação social devem avaliar se os feitos a informar que afetam a privacidade são ou não de relevância pública; se não o são, o silêncio é a conduta constitucionalmente exigida. Até porque, após a publicação de fatos que não sejam de relevância pública, denegrindo e afetando a vida privada e intimidade do indivíduo, causa-lhe dano irreversível e irreparável. Posteriormente à violação do direito, qualquer palavra que se tente emitir com sentido de escusa não ajudará a eliminar a lesão à privacidade e intimidade. Afinal, as palavras depois de proferidas não voltam atrás.

Ascensão (1998, p. 97), privativista clássico do Direito Internacional, por sua vez, ensina que o direito a individualidade, inerente à classificação do direito de personalidade, pode ser dividido, segundo Hubmann, em três esferas: individual, privada, e secreta.

Diz Ascensão (1998) que a esfera individual protege o homem em relação à sociedade, quanto a sua identificação pessoal e sua imagem, e ainda quanto ao valor da honra. A esfera privada, por outro lado, concentra-se na privacidade, como uma defesa da autonomia necessária à pessoa para que não seja absorvida pela comunidade. Por último, a esfera secreta corresponde aos aspectos de reserva absoluta, inerente ao conhecimento e consciência de cada indivíduo, sendo por isso mais densa. Enfim, o autor ainda insiste em lembrar que esse direito à intimidade não pode se tornar um super-direito.

Bem, em se tratando, pois, de Direito Fundamental Individual, a privacidade e a intimidade efetivamente merecem guarida jurisdicional intensa, observados os ditames constitucionais e infraconstitucionais.

Por outro lado, cumpre aferir como o sistema jurídico brasileiro trata - em nível constitucional e infraconstitucional - desse Direito.

A Constituição Federal do Brasil, em seu art. $5^{\circ}$, inc. X, estabelece como princípio fundamental da República que são invioláveis a intimidade, a vida privada, a honra e a imagem das pessoas, assegurado o direito à indenização pelo dano material ou moral decorrente de sua violação.

A despeito disso, é preciso que ter em conta aqui a necessária leitura sistemática do ordenamento jurídico pátrio no ponto. ${ }^{5}$ E por que isso? Porque o Texto Constitucional, para o que interessa ao caso debatido, igualmente prevê em seu art. $5^{\circ}, \mathrm{XXXV}$, o princípio da inafastabilidade do controle judicial, e no art. 102, I, $a$, II, $a$ e $b$, III, $a, b$ e $c$, e no art. 103, $\$ 2$, o princípio da constitu-

\footnotetext{
${ }^{5}$ A partir de Canaris (1996, p. 83), a ideia de sistema se sustenta em razão de alguns pressupostos: necessidade de um mínimo de racionalidade na dogmática; da identificação das instituições com sistemas de ações e de interações, o do próprio direito como um sistema de comunicações; o do apoio sociológico da estruturação jurídica; e o do tipo do pensamento dos juristas.
} 
cionalidade dos atos estatais, ao dispor sobre os mecanismos assecuratórios da ordem constitucional e seus remédios/instrumentos protetivos.

Em face disso pode-se afirmar, com Chequer (2011, p. 68), que a honra não pode configurar obstáculo impeditivo de acesso à informação, por exemplo, relacionada com investigações sobre cometimento de violações de direitos, eis que, nesses casos, o dano à honra da pessoa atingida pela matéria informativa ou pela expressão veiculada não se origina da veiculação da notícia, mas sim da própria conduta daquele que foi investigado, acionado em juizo ou preso. ${ }^{6}$

Assim, por mais que a norma constitucional - e o sistema jurídico como um todo - estabeleçam catálogos de direitos e garantias constitucionais referidas como autoaplicáveis, e disso não se têm dúvidas, o fenômeno de efetivação concretizante destes sempre contará com graus/medidas passíveis de mensuração, e estas, definitivamente, não estão dadas pela Carta Política, demandando do intérprete/aplicador atribuição de sentido racional e material às suas reivindicações, caso por caso (que inclusive pode tratar de interesse coletivo, difuso ou individual homogêneo), levando em conta o universo de variáveis que convergem a ele.

Por sua vez, o Novo Código Civil brasileiro, em seu Livro I, Título I, Capítulo II, art. 11 e seguintes, regulamentou ainda mais o tema sob comento, destacando,dentre outras coisas:

a) o fato de que toda a pessoa tem direito ao nome, nele compreendidos o prenome e o sobrenome (art. 16);

b) o fato de que, salvo se autorizadas, ou se necessárias à administração da justiça ou manutenção da ordem pública, a divulgação de escritos, a transmissão da palavra, ou a publicação, a exposição ou a utilização de imagem de uma pessoa poderão ser proibidas, a seu requerimento e sem prejuízo da indenização que couber, se lhe atingirem a honra, a boa fama ou a respeitabilidade, ou se destinarem a fins comerciais (art. 20);

c) o fato de que a vida privada da pessoa natural é inviolável, e o juiz, a requerimento do interessado, adotará as providências necessárias para impedir ou fazer cessar ato contrário a essa norma (art. 21).

Em outras palavras, há determinadas qualidades que caracterizam a dignidade da pessoa, entre elas, o respeito dos concidadãos (honra subjetiva e objetiva), o bom nome, a imagem e a reputação, e por tal razão devem ser observados (CARVALHO, 2002, p. 94). Perez Luno (1999, p. 335) lembra nesse particular que se tratavam destas questões como o direito das pessoas à fama e reputação, bem como direito à tranquilidade do espírito e à solidão.

\footnotetext{
6 Lembra o autor que a Corte Europeia de Direitos Humanos condenou o Estado Austríaco pelo fato de que um Tribunal doméstico seu condenara jornalista por críticas duras feitas ao então chanceler da Áustria, Bruno Kreisky, por ter ele sido benevolente para com os nazistas durante a Segunda Guerra Mundial, violando, assim, o direito fundamental à expressão e informação.
} 
Em verdade, não existe uma classificação definida de Direitos Fundamentais estanques. No entanto, nessa lista de direitos particularizados, existem direitos que podem ser reconhecidos como direitos de privacidade; existem, também, outros direitos às vezes referidos como direitos de personalidade, e, baseada na privacidade e baseada em propriedade, existem, ainda, a proteção da imagem e a proteção de sua reputação. Há direitos que se relacionam com sua integridade física, com a intimidade de seu corpo e as circunstâncias da concepção. De fato, intimidade, privacidade e integridade são frequentemente usados de forma sinônima.

Todos estão unidos à noção geral de dignidade, e esta é, ela mesma, identificada como um atributo separado de cada pessoa, inclusive sendo uma noção abrangente da condição humana. $\mathrm{Na}$ verdade, dignidade requer a aceitação de um alto nível de respeito pela maneira como uma pessoa modela sua vida privada. A vida privada é, sobremaneira e, felizmente, diferente a todos. E isso mostra/anuncia não apenas a sua diversidade e a sua escolha de intimidade, mas também seu enigma e sua subjetividade.

No entanto, na vida privada de uma pessoa, sua intimidade não se limita a suas emoções ou aos seus sentimentos ou, ainda, a sua privacidade. Há que se fazer uma espécie de equilíbrio aos contatos com as relações da coletividade.

Esse direito de intimidade poderia, inclusive, quem sabe, pertencer a uma nova categoria de lei privada de "direitos civis de igualdade". Esses direitos estão vinculados a noções de igualdade perante a lei e à proteção contra a ilegalidade da discriminação.

O direito à intimidade, em geral, diz respeito ao status e a capacidade de realizar atividades específicas. O status é entendido como tendo dois componentes clássicos: status civitatis (nacionalidade) e status familiae (status familiar), embora outras noções de status, idade, saúde, profissão ou profissão da pessoa tenham surgido.

Não se pode esquecer, também, que existem consequências patrimoniais e extrapatrimoniais nesse "direito à intimidade". Patrimonialmente, por exemplo, pode-se ter uma associação íntima que se refere aos compromissos voluntários de uma pessoa de adquirir ativos e assumir passivos na presença próxima de outro (e para a pessoa lucro ou prejuízo). Já de forma extrapatrimonial, a intimidade se relaciona com o direito de privacidade do pessoal, econômico, social e sexual, ou seja, com aspectos de sua associação íntima (e os deveres de reconhecimento da intimidade dos outros).

De certa forma, seus direitos comprometem a pessoa com a sua libertação e com seus deveres. $O$ respeito de sua intimidade é companheiro de seu respeito à intimidade de outros da coletividade, em quem os seus direitos estão ligados.

Em sua maior parte, o significado da intimidade foi entendido em termos de liberdades fundamentais e aprovação ou desaprovação das relações sexuais íntimas pelas leis públicas, ou em termos de casamento e desaprovação do direito privado de relações não conjugais, e seu único interesse pelo casamento como generativo da família e, daí, do status pessoal de um cidadão e lar de sua jurisdição jurídica personalidade. 
Um aspecto é certo: o direito de privacidade não se confunde com o de intimidade. Representando este o núcleo mais reservado e indevassável da vida de determinada pessoa, em nada interessando à opinião pública o que faz ou deixa de fazer, pensar, sentir, fruir, etc., desde que não interferindo de forma invasiva na vida de outras pessoas. ${ }^{7}$

O importante, neste trabalho, é analisar que os argumentos que justificam, ou tentam justificar a decisão, amoldam-se com a chamada jurisprudência dos valores, assim entendida como uma linha teórica argumentativa desenvolvida a partir da distinção entre regras e princípios, estes entendidos como mandamentos de otimização, isto é, ordem de realizar algo da melhor maneira possível entre as existentes, prescindido também da diferenciação entre os discursos de justificação e aplicação das normas, uma vez que, nesse marco, os argumentos de espectro axiológico, moral, pragmático e ético são válidos tanto nos discursos de justificação - que objetivam a positivação de normas e referem-se à validade destas - quanto nos discursos de aplicação - destinados à dedução lógica de qual a norma, dentre as prima facie aplicáveis, é adequada ao caso.

Veja-se, a partir de agora, como essas questões se projetam no âmbito de caso concreto decidido pelo Segundo Grupo Criminal do Tribunal de Justiça do Estado do Rio Grande do Sul.

\section{Estudo de caso}

O caso que se passa a analisar refere-se a embargos infringentes opostos por Carlos Alexandre Rodrigues Gonçalves, em face do acórdão de proferido pela Quarta Câmara Criminal do Tribunal de Justiça do Estado do Rio Grande do Sul, pelo qual, por maioria, foi mantida a denegação da ordem de Habeas Corpus (HC) proferida na origem, restando vencido o Relator do feito, que a concedia para fazer cessar coação ilegal sofrida pelo paciente, médico, pelo fato de a autoridade policial requisitar prontuários de duas vítimas de tentativas de homicídio, com indiferença ao sigilo respectivo, e procedendo à advertência de o descumprimento da requisição implicar a tipificação do crime de desobediência.

Aliás, o Delegado de Polícia fez tal solicitação para instruir investigação policial sobre aqueles homicídios, no intento de fundamentar ainda mais a persecução do responsável por tais crimes.

Percebe-se, pelo exposto, que a jurisprudência dos valores, pressupondo ser a constituição uma ordem concreta de valores, faz uma confusão entre Direito (aquilo que é devido, obrigatório ou permitido) e valores (aquilo que é negociável e passível de preferências), negando, então, o caráter obrigatório do Direito. Além do mais, prescinde da limitação de espectro argumentativo imposta pela distinção entre os discursos de aplicação e justificação.

Os fundamentos que levaram o Relator do processo do HC na Quarta Câmara Criminal, Dr. Mauro Borba, a votar, estabeleceram-se da seguinte forma:

\footnotetext{
$\overline{7}$ No Brasil ver os textos já clássicos de Pontes de Miranda (1995), Gomes (2000) e França (1999).
} 
Com efeito, o prontuário médico, na medida em que contém todas as informações relevantes obtidas durante atendimento médico hospitalar está abrangido pelo dever de sigilo que se impõe ao profissional médico justamente em razão da proteção constitucional à intimidade do paciente, conforme estabelece o art. 5o, inc. X, da Constituição Federal e art. 207, do Código de Processo Penal. O art. 154 do CP prevê que é conduta passível de punição revelar a alguém, sem justa causa, segredo, de que tem ciência em razão de função, ministério, ofício ou profissão, e cuja revelação possa produzir dano a outrem. Exceções à proteção do sigilo profissional, no entanto, são estabelecidas nas próprias normas legais: consentimento por escrito do paciente, motivo justo (justa causa) e dever legal. E, nos termos do Código de Ética Médica - Resolução no 1.931/09, do Conselho Federal de Medicina (art. 73) - é vedado ao médico revelar fato de que tenha conhecimento em virtude do exercício de sua profissão, salvo por motivo justo, dever legal ou consentimento, por escrito, do paciente.

O revisor do feito na Quarta Câmara Criminal, Des. Julio Cesar Finger, divergiu do Relator, sob os argumentos de que: (1) o sigilo médico-profissional não é um direito absoluto, circunstância reconhecida, inclusive, no próprio Código de Ética Médica (Resolução n. 1.931/09), que o excepciona nas hipóteses legais; (2) ao Delegado de Polícia, conforme dispõem o art. $6^{\circ}$, III, do CPP8, e o art. $2^{\circ}$, $\$ 2^{\circ}$, da Lei n. $12.830 / 12$, no curso das investigações de um crime, compete, logo que tiver conhecimento da prática de infração penal, colher todas as provas que servirem para o esclarecimento do fato e suas circunstâncias, cabendo a ele ainda requisitar perícia, informações, documentos e dados que interessem à apuração do ocorrido;' (3) na espécie, o Delegado de Polícia requisitou os prontuários médicos de duas supostas vítimas de homicídio, evidenciando-se de forma clara a justa causa para o pedido, critério que já afasta o suposto impeditivo - invocado pelo recorrente - para o fornecimento de dados, qual seja, o art. 73 do Código de Ética Médica. ${ }^{10}$

Lembrou, ainda, o Revisor do HC algumas das razões do Ministério Público nos autos, ${ }^{11}$ confortadoras de sua posição externada: (1) ao ocorrer um crime, surge para o Estado o dever/poder de punir o agente delituoso, ocorrendo o exercício do "jus puniendi" por meio da persecução criminal, a qual possui duas fases: a investigativa e a processual. A fase investigativa ocorre por meio do inquérito policial, o qual é presidido pela autoridade policial, a quem, para que se chegue à verdade dos fatos, incumbe realizar vários atos necessários ao deslinde da investigação. As diligências a serem realizadas pela autoridade policial, durante a confecção do inquérito policial, encontram-se arroladas no artigo $6^{\circ}$, do Código Processo Penal, entre elas a colheita de provas e a determinação de perícias;

\footnotetext{
8 Art. 6. Logo que tiver conhecimento da prática da infração penal, a autoridade policial deverá: [...] III - colher todas as provas que servirem para o esclarecimento do fato e suas circunstâncias.

9 Art. 2. As funções de polícia judiciária e a apuração de infrações penais exercidas pelo delegado de polícia são de natureza jurídica, essenciais e exclusivas de Estado. [...] \2. Durante a investigação criminal, cabe ao delegado de polícia a requisição de perícia, informações, documentos e dados que interessem à apuração dos fatos.

10 Art. 73. Revelar fato de que tenha conhecimento em virtude do exercício de sua profissão, salvo por motivo justo, dever legal ou consentimento, por escrito, do paciente. Parágrafo único. Permanece essa proibição: a) mesmo que o fato seja de conhecimento público ou o paciente tenha falecido; b) quando de seu depoimento como testemunha. Nessa hipótese, o médico comparecerá perante a autoridade e declarará seu impedimento; c) na investigação de suspeita de crime o médico estará impedido de revelar segredo que possa expor o paciente a processo penal.

11 No Segundo Grau os Drs. Dirce Soler e Silvio Miranda Munhoz.
} 
(2) a investigação criminal, no caso, é uma justa causa com nítido caráter de interesse público; (3) não apenas a obtenção do prontuário hospitalar, mas diversos outros atos investigativos, como apreensão de objetos (artigo $6^{\circ}$, II, do CPP), requisição de perícias (artigo 6º, VII, do CPP) e ação controlada no crime organizado (artigo $8^{\circ}$, parágrafo $1^{\circ}$, da Lei n. 12.850/13) podem ser realizados de ofício pelo delegado de polícia, sem a necessidade de autorização judicial; (4) somente haveria violação ao sigilo profissional se o recorrente expusesse - mediante revelação de segredo - um paciente a processo penal, sendo este o suspeito da prática de um crime; (5) nesse feito, o Delegado de Polícia requisitou do recorrente os prontuários médicos das vítimas; (6) a autoridade policial requisitou prontuário de atendimento das vítimas para comprovação da materialidade do crime, o que torna incabível a alegação de proteção ao paciente, pois este não será prejudicado pela investigação. Pelo contrário, ele será beneficiado, pois seu agressor será responsabilizado criminalmente por seus atos. ${ }^{12}$

O Relator dos referidos embargos infringentes no Segundo Grupo Criminal, Des. Sérgio Miguel Achutti Blattes, apresentou proposta de decisão no mesmo sentido do voto minoritário, na origem, do Dr. Mauro Borba, agregando ainda os seguintes fundamentos: (1) não paira dúvida de que o prontuário médico, na medida em que contém todas as informações relevantes obtidas durante atendimento médico hospitalar, está abrangido pelo dever de sigilo que se impõe ao profissional médico, justamente em razão da proteção constitucional à intimidade do paciente; (2) que o Código de Ética Médica - Resolução n. 1.931/09, do Conselho Federal de Medicina (2009) - disciplina ser vedado ao médico "revelar fato de que tenha conhecimento em virtude do exercício de sua profissão, salvo por motivo justo, dever legal ou consentimento, por escrito, do paciente", e nenhuma dessas situações ocorreram no feito; (3) que por motivo justo deve ser compreendido aquele que diretamente envolver direito ou garantia fundamental de terceira pessoa, nos casos em que o sigilo das informações referentes ao paciente possa, de alguma maneira, lesar terceiros; (4) na medida em que o acesso ao prontuário médico constitui restrição do direito/garantia fundamental à intimidade, impõe-se concluir que somente mediante ordem judicial ele poderia ser disponibilizado, o que igualmente não ocorreu no caso.

Por fim, concluiu o Relator dos embargos infringentes que a requisição da autoridade policial em ofício diretamente remetido ao nosocômio não se insere nas excepcionais situações em que

\footnotetext{
$\overline{12}$ É importante ainda destacar o alerta que o Ministério Público fez nestes autos: "O caso em exame, aliás, revela uma prática há muito adotada pelas direções dos hospitais que recebem feridos nos setores de pronto atendimento em todo o Estado do Rio Grande do Sul. Em nome do sigilo médico, recusam-se esses estabelecimentos a fornecerem à autoridade policial e aos membros do Ministério Público documentos necessários à comprovação da materialidade de crimes graves, praticados com extrema violência, atrasando a investigação, inviabilizando a propositura da ação penal cabível, desperdiçando o dinheiro do contribuinte, e fazendo com que as vítimas permaneçam, muitas vezes, à mercê de seus agressores por tempo desnecessário, até que, depois de inúmeras requisições descumpridas, somente com a movimentação do Poder Judiciário obtenha-se, finalmente, uma requisição que entendam as direções dos hospitais mereça efetivo cumprimento. E esse entrave, que, aparentemente, decorre de um conflito de autoridades, vem, inegavelmente, em prejuízo de toda a sociedade. Já é tempo de enfrentar-se essa delicada questão, especialmente porque hoje o Rio Grande do Sul vive momento singular, de incontrolável criminalidade, e de parcos recursos para enfrentá-la. O interesse da sociedade deve prevalecer sobre qualquer outro - respeitadas as garantias constitucionais, e esse interesse é de que a autoridade policial tenha razoáveis condições de cumprir o seu munus."
} 
a quebra de sigilo médico é admitida, o que torna imperioso concluir se tratar a requisição da autoridade policial, alicerçada sob sanções legais, de constrangimento ilegal.

Em face do todo ponderado, entendeu-se nesse julgamento que se fazia necessário um exercício de tentativa de harmonização das normas coligidas pelas partes e julgadores, não perdendo de mira os fatos a elas relacionados. Fala-se, em especial, dos seguintes dispositivos: art. $6^{\circ}$ e $2^{\circ}$, $\mathbb{S}$ $2^{\circ}$, da Lei n. 12.830/12, que autoriza ações das autoridades policiais em investigações institucionais; Código de Ética Médica, em seus arts. 73, 89 e 102 (Resolução n. 1.931/09), regulamentando a relação entre médico e paciente, inclusive no que toca ao resguardo das informações deste; art. 154 do Código Penal, tipificando a violação de segredo profissional; e art. 207 do Código de Processo Penal, tratando da proibição de depoimento das pessoas (testemunhas) que têm o dever de sigilo em razão da profissão.

Como realizar, então, tais harmonizações? Da seguinte forma:

a) o Direito Fundamental protegido pelo art. $5^{\circ}$, inc. X, enquanto princípio informativo da República e do Estado Democrático de Direito, deve ser protegido em caráter primordial;

b) esse Direito Fundamental apenas pode ser atingido em termos de flexibilização diante de situações absolutamente justificadas pelo próprio sistema normativo; se o for de maneira indevida, está prevista a indenização por danos material ou moral eventualmente ocorridos.

Sustenta-se que há situações fáticas e normativas que podem autorizar o acesso à privacidade das pessoas físicas e jurídicas, algumas estando explicitamente dispostas em normas infraconstitucionais tópicas, como o caso, no Brasil, da autorização para serem feitas escutas telefônicas e em outras formas de comunicação, como a telemática.

E por que isso ocorre? Porque também a segurança pública e o combate à criminalidade e violência são interesses públicos indisponíveis do Estado e da Sociedade, cada vez mais ameaçados por condutas de alta periculosidade e risco, o que demanda processos de harmonização e equilíbrios, por vezes tensos, à proteção de bens jurídicos distintos, mas com igual estatura normativa.

Os discursos jurídicos de aplicação possuem como finalidade a dedução lógico-racional de qual norma, entre as prima facie aplicáveis, é a mais acertada ao caso concreto. Aqui, entende-se, a partir de um exaurimento, partindo de uma reformulação da situação de fato da casuística, um constante agravamento, visando ao engendramento da corresponsabilidade e do policentrismo da elaboração e policiamento das decisões judiciais. Vejam-se as lições de Habermas (1997, p. 322-323):

[...] encontrar entre as normas aplicáveis prima facie aquela que se adapta melhor à situação de aplicação descrita de modo possivelmente exaustivo e sob todos os pontos de vista relevantes. É preciso estabelecer um nexo racional entre a norma pertinente e as normas que passam para o pano de fundo, de tal modo que a coe- 
rência do sistema de regras permaneça intocada em seu todo. As normas pertinentes e as retroativas não relacionam entre si como valores concorrentes, os quais, na qualidade de mandamentos de otimização, seriam realizados em diferentes níveis: porém, como normas "adequadas" ou "não-adequadas". Ora, adequação significa a validade de um juízo deduzido de uma norma válida, através do qual a norma subjacente é satisfeita.

Assim, Habermas (1997, p. 284) chama a atenção para um aspecto de suma importância: a consideração (participação) dos interesses dos interlocutores participantes no discurso de aplicação, nos seguintes termos:

Questões de aplicações de normas afetam a auto compreensão e a compreensão do mundo dos participantes, porém não do mesmo que os discursos de fundamentação. Nos discursos de aplicação, as normas, supostas como válidas, referem-se sempre aos interesses de todos os possíveis atingidos; no entanto, quando se trata de saber qual norma é adequada a um acaso determinado, essas relações se retraem atrás dos interesses das partes imediatamente envolvidas.

Contrariamente à teoria exposta, Alexy (1999, p. 27) aduz que o discurso jurídico se trata de um caso especial comparando ao discurso prático geral, distinto este do primeiro somente pelo fato daquele ser legitimado por sua institucionalização por normas. Conclui-se, assim, que seria autorizado que os componentes dos discursos de aplicação valessem de argumentos morais.

Por esse raciocínio, nota-se uma aproximação na relação de sua definição e distinção dos discursos de aplicação baseados em sua teoria dos princípios, na qual os diferencia das regras e, fundamentalmente, do seu método de realização.

Com base no exposto, em voltando à casuística deste leading case, tem-se que, nas investigações policiais, os delegados de polícia poderiam requisitar perícias, informações, documentos e dados que interessam à apuração dos fatos, nos termos do art. $2^{\circ}, \mathbb{S} 2^{\circ}$, da Lei n. 12.830/2013, o que fora feito no caso sob análise. O Estado, para cumprir sua função de "garante" da ordem pública e responsabilizar quem a viola, tem de ter instrumentos eficazes de ação e reação - óbvio que tudo isso fundado em ordem jurídica democraticamente instituída.

Veja-se que mesmo a legislação citada pelo Relator dos Embargos analisados refere que a punição estabelecida pelo art. 154 do Código Penal Brasileiro é somente para aquele que, sem justa causa, revele segredo obtido por conta de função, ministério, ofício ou profissão, e cuja revelação possa produzir dano a outrem. Da mesma forma, o Código de Ética Médica, em seu art. 73, sinaliza que, por motivo justo, dever legal ou consentimento, por escrito, do paciente, será possível a revelação de fato que o médico tenha conhecimento por decorrência do exercício de sua profissão (havendo previsão, ainda, de que, na investigação da suspeita de crime, o médico estará impedido de revelar segredo que possa expor o paciente a processo penal).

O art. 207 do Código de Processo Penal, por sua vez, quando proíbe a revelação de segredo ou de intimidade de alguém, obtido de igual sorte por conta de profissão, o faz somente às testemu- 
nhas, quando estiverem prestando informações em juízo, o que não é o caso aqui, eis que o prontuário dizia respeito às vítimas fatais do crime praticado.

O Direito Fundamental à Intimidade e Privacidade pode ter diferimento de tratamento em situações muito especiais e exclusivamente reguladas pela lei. $\bigcirc$ que ocorre na espécie, isso porque o Delegado de Polícia cumpriu suas funções institucionais na busca de elementos para o inquérito investigativo, solicitando informações do prontuário médico de potenciais vítimas de homicídio, importantes na delimitação do caso investigado.

Outra questão é saber se o nosocômio - e os médicos - poderiam conceder acesso a tais prontuários. Também é afirmativa a resposta, porque estavam atendendo à postulação oficial do Estado, com base em justa causa e motivo justo (investigação policial de homicídio).

\section{Conclusão}

Ainda e como se disse, se tais informações veiculadas pelos prontuários fornecidos causarem prejuízo às partes envolvidas, é a própria Constituição que prevê a possibilidade de indenização, o que deve ser procurado em jurisdição própria.

E mais, o que foi exposto pelos prontuários médicos não fez referência em nada da esfera privada ou secreta dos envolvidos, âmbitos de intangibilidade constitucional diferidos à proteção, mas tão somente trouxe informações importantes à responsabilização de quem cometeu os homicídios investigados.

Por tais razões se votou pela improcedência dos Embargos Infringentes, no que foi acompanhado pela maioria do Segundo Grupo Criminal do Tribunal de Justiça do Estado do Rio Grande do Sul.

\section{Referências}

ALEXY, Robert. Teoria dos Direitos Fundamentais. São Paulo: Atlas, 2010.

ALEXY, Robert. 'La tesis del caso especial'. Isegoría, Madrid, n. 21, p. 23-35, 1999.

ASCENSÃO, José de Oliveira. Direito Civil: Teoria Geral. Coimbra: Coimbra, 1998.

BARBOSA, Álvaro Antônio do Cabo. Direito à própria imagem. Aspectos fundamentais. São Paulo: Saraiva, 1989.

CANARIS, Wilhelm Canaris. Pensamento sistemático e conceito de sistema na ciência do direito. Lisboa: Fundação Calouste Gulbenkian, 1996.

CARVALHO, Márcia Haidée Porto de. A defesa da honra e o direito à informação. Florianópolis: Letras Contemporâneas, 2002. 
CHEQUER, Cláudio. A liberdade de expressão como Direito Fundamental preferencial prima facie. Rio de Janeiro: Lúmen Júris, 2011.

CONSELHO REGIONAL DE MEDICINA. Resolução CFM n. 1.931/09. Código de Ética Médica, de 17 set. 2009. Brasília, DF, 2010. Disponível em: <https://portal.cfm.org.br/images/stories/biblioteca/codigo\%20de\%20etica\%20medica.pdf>. Acesso em: 02 mar. 2012.

FARIAS, Edilsom Pereira de. Colisão de Direitos - A Honra, A Intimidade, A Vida Privada e a Imagem versus A Liberdade de Expressão e Informação. 2. ed. Porto Alegre: Sérgio Antonio Fabris Editor, 2000.

FRANÇA, Rubens Limongi. Instituições de Direito Civil. São Paulo: Saraiva, 1999.

GENTOT, Michel. Access for Information and Protection of Personal Data. Commission Nationale de l'Informatique ET des Libertés. Disponível em: <http://www.pcpd.org.hk/e nglish/infocentre/ files/gentot-paper.doc>. Acesso em: 02 mar. 2012.

GOMES, Orlando. Introdução ao Direito Civil. Rio de Janeiro: Forense, 2000.

HABERMAS, Jürgen. Direito e democracia: entre facticidade e validade. Rio de Janeiro: Tempo Brasileiro, 1997. (Biblioteca Tempo Universitário, 101/102).

LEAL, Rogerio Gesta. Estado, Administração Pública e Sociedade: novos paradigmas. Porto Alegre: Livraria do Advogado, 2006.

LEAL, Rogerio Gesta. O Estado-Juiz na Democracia Contemporânea: uma perspectiva procedimentalista. Porto Alegre: Livraria do Advogado, 2007.

NOGUEIRA ALCALÁ, Humberto. Derechos fundamentales y garantías constitucionales. Santiago de Chile: Librotecnia, 2013.

PÉREZ LUÑO, Antonio Henrique. Derechos Humanos, Estado de Derecho y Constitución. Madrid: Tecnos Ltda, 1999.

PONTES DE MIRANDA, Francisco Cavalcanti. Tratado de Direito Privado. Direito de Personalidade. Direito de Família. Rio de Janeiro: Borsoi, 1955.

PROSPERI, Massimo. La tutela dell'immagine. Roma: Giappichelli Editore, 2010.

SILVA, Edson Ferreira da. Direito à Intimidade. São Paulo: Oliveira Mendes, 1998.

Data da submissão: 24 de novembro de 2017 Aceito em: 08 de dezembro de 2017 
